\title{
LIFTING THE BARRIERS TO INNOVATION
}

\author{
A Practical View from the Trenches
}

\author{
Jim Brown \\ Draeger Safety UK Ltd, Northumbria University, UK
}

\begin{abstract}
Draeger Safety UK based in Blyth Northumberland manufacturing breathing apparatus for the search and rescue market has been following the path to organizational learning for several years. So far, this path has entailed individual and group learning, leading to practical application of that learning and knowledge in innovative improvement projects and problem solving process. This paper examines the practical view from the trenches of the efforts of the organization at all levels to lift the barriers to innovation from several academic perspectives. These perspectives include Stafford Beer's Viable System Model, Peter Drucker's seven sources of innovation and Margaret Wheatly's argument that innovation means relying on the creativity of everyone within the organization. However, the purpose of Draeger Safety UK in cybernetic terms is survival through the generation of profit from its core activity of breathing apparatus manufacture. Therefore resources of both time and finance must remain balanced between the activities that produce today's profit and the innovation based forward drive to all round improvement that ensures tomorrows. Thus lifting the barriers to innovation is the conscious decision to utilise resources in equipping staff with the knowledge, tools and opportunities to enable innovation to take place. While at the same time the view from the trenches is the comparison of academic theory and practical reality.
\end{abstract}

Key Words: Knowledge, Organizational learning, Viable Systems, Innovation

\section{INTRODUCTION}

Some look on innovation as flashes of inspiration others just as hard work and planning. (Drucker, 2002) holds a position between the two leaning more to the hard work end of the spectrum. Arguing some innovation comes from flashes of genius, but most from a purposeful search 
for innovation opportunities. He holds the view that as with other organizational activity, innovation must be deliberately managed, targets set and results monitored. However he also maintains that innovation is more knowing than doing, being a special function of enterprise that must be committed to the systematic practice of innovation through knowledge.

Draeger Safety UK also holds this belief, having followed the path towards a learning organization for several years.

This paper examines the activities and results over these years to embrace principles of innovation through knowledge building, active participation and the development of trust at all levels within the workforce. The paper will utilise three themes to examine and place into academic context the practical activities carried out by the management and staff of Draeger Safety UK. The themes being Stafford Beer's Viable System Model, Peter Drucker's seven sources of innovation and Margaret Wheatly's argument that innovation means relying on the creativity of everyone within the organization. It is not the intention to give a definitive answer to organizational innovation; merely to examine the Draeger Safety UK approach. While this approach works for Draeger Safety UK within other organizations, it may not.

Innovation has many definitions including:

"Innovation is the successful exploitation of new ideas and is a vital ingredient for competitiveness, productivity and social gain within businesses and organizations."-London Innovation definition

"The introduction of something new"- dictionary definition

"An innovative business is one which lives and breathes 'outside the box'. It is not just good ideas, it is a combination of good ideas, motivated staff and an instinctive understanding of what your customer wants." Richard Branson - DTI Innovation lecture, 1998

"Once you've worked on a truly innovative project you realise how important transformation is to the success or failure of a project. Your way of thinking changes your priority changes, your company changes and your way of working changes forever. True innovation is not just about changing a product, a service or even a marketplace it's also about recognising and realizing the need to change yourself." Ralph Ardill, Marketing \& StrategicPlanning Director, Imagination - London Innovation Conference, 2003

Therefore within this paper innovation will be looked upon as any new product, method, or process that brings improvement and competitive advantage. 
Today we live in an ever-changing world; a world where the speed of change increases every year and the need for organizations to adapt to change is not only important but also imperative to continued prosperity. An era requiring rapid change where to stand still is to fall behind, left behind in the survival race overtaken by competitors reacting to the requirements of change. Organizations are finding themselves on an exponential curve requiring ever faster adaptation and change (Wheatley, 2001). To survive organizations must change and adapt with ever increasing rapidity. The simple result of this requirement is that the acquisition and use of knowledge by individuals, groups and organizations, as the basis for innovation is becoming, if not already has become, an essential organizational survival tool.

Social anthropologists (Morris, 1967, 1969) tell us that people naturally wish to learn, explore new challenges, investigate new environments and adapt to changing conditions. This is part of human nature; in other words, people are natural innovators. In the past organizations have deliberately stifled natural innovation in the name of standardization, efficiency, predictability, reduction of variability etc to such an extent they have become barriers that must be overcome in today's rapidly changing environment.

\section{LIFTING THE BARRIERS}

Throughout both the private and public sectors traditionally several barriers to innovation have been in place. The challenge to senior management is in lifting these barriers. Barriers such as time allocation, finance, and innovational demarcation in the past have prevented involvement of all members of an organization in innovational activity. While the three barriers mentioned are not a full list. They form major obstacles to innovational progress.

\subsection{The Time Barrier}

For individuals or groups to engage in learning and innovation, time allocation is required. If the organizational culture denies the need for allocation of time for such activities innovation is impossible.

Recently the move to the so-called lean mean organization has been in vogue. This has lead to in some cases to 'streamlining', 'downsizing' and other practices that in effect have reduced staff numbers and increased the workload for remaining staff. Some organizations have pursued this path to such an extent; reaction to change and innovation are virtually impossible. 
Staff being more than fully occupied in meeting daily requirements. In fact this practice has brought reengineering into disrepute (Willets, 1996). Leaving staff highly suspicious of management motives when introducing efficiency and effectiveness programs, reducing trust and further stifling innovation.

'Lean is mean and doesn't even improve long term profits' (Mintzberg, 1996)

For all staff to become enthusiastically involved as (Willets, 1996) maintains is the way forward to rapid innovation. The establishment of a trusting cooperative environment is a prerequisite. However, for increased trust time saved and improvements must be seen as beneficial to the whole workforce and not just management and profit.

At Draeger Safety UK, time is available for individuals to be able to engage in training and educational activities. This then leads to better understanding and if innovation is more knowing than doing (Drucker, 2002), thereby increases the innovation opportunities available within the organization.

This has enabled an enforcing systems thinking (Senge, 1990) feedback loop (Figure 1) to develop within Draeger Safety UK. Thus enabling learning and innovation with all members of staff becoming involved and being allowed the time to do so.

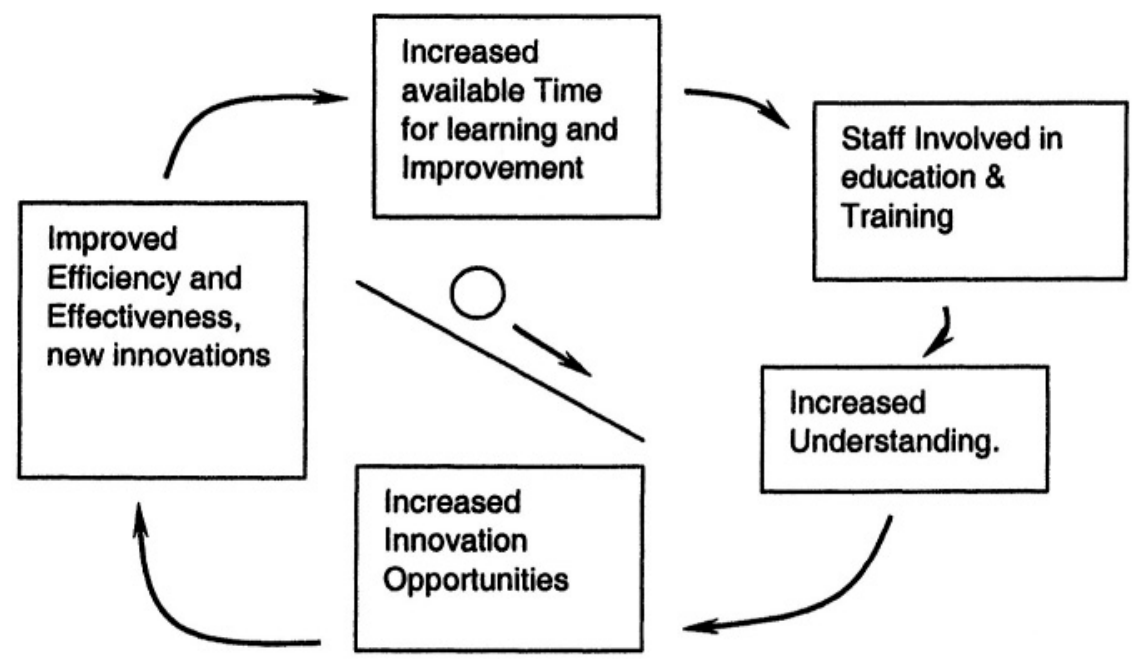

Figure 1. Positive Reinforcing Feedback Loop (Senge, 1990)

The Positive Reinforcing Feedback Loop shown above demonstrates the systems thinking thought processes behind the personal and organizational learning within Draeger Safety UK. Time is available for people to partake 
in training and education. Thus increasing understanding of general operational, managerial and improvement principles as well as specific knowledge of products equipment and operations etc, this leads to increased understanding providing increased innovational opportunities.

Draeger Safety UK and specifically the operations department capitalize on such opportunity via kaizen groups, problem solving teams Draeger Best teams, (Draeger Best is a form of the European Foundation for Quality Management Model and practice EFQM) and action teams. This has resulted in a more involved workforce, increased trust and the empowerment of individuals. In addition, the formation in January 2003 of a dedicated team entitled the "High Performance Work Team". Consisting of four individuals drawn from Quality, Design, Assembly Supervision and Industrial engineering, providing cross-functional abilities, has increased the innovational potential within the company

The team's purpose is one of dedicated attention to management identified areas of concern where improvement is either required or desirable.

Any positive response loop such as that described above also has a balancing loop that is often unseen, forgotten or ignored (Senge, 1990). For example in the loop shown in figure 1, available time and innovation can not grow indefinitely, sooner or later a state of balance or equilibrium will be established by management or will naturally establish itself. When the loop is implemented innovations may increase slowly until staff generally recognizes the benefit, then increase more rapidly as use is made of the learning innovation time loop. However as the easily attained innovations 'or low hanging fruit picked as some writers have termed it are attained the pace of innovation will slow and find a stable level. This level can be controlled and maintained via time and resource allocation in a managed environment or be allowed to establish itself at some arbitrary level in an unmanaged one. In an uncontrolled environment, this level can also change for what seems no apparent reason. It is far more desirable from a systems control respect that management determines and controls this level to suit the needs of the organization rather than allow arbitrary events to have affects in ways sometimes not visualized or desired.

\subsection{The Innovation Demarcation Barrier}

Draeger Safety UK has also tackled the innovation demarcation barrier, the belief that "only designers, industrial engineers, managers, people with degrees etc are capable of innovative thinking" and therefore allowed the opportunity to become involved in innovation. Termed 'academic snobbery' by one senior manager. This belief stifles large possible sources of 
innovative creativity, can cause frustration and certainly lose organizations holding this view to innovation competitive advantage opportunities. The formation of the High Performance Work Team might form the impression that in fact Draeger Safety UK does believe in demarcation, where innovation and creative thinking is concerned. However, this team is in addition to, not instead of alternative innovational activities. In some cases with the 'High Performance Work Team' functioning as a resource or facilitation medium for other improvement teams. Management ensures that 'academic snobbery' in not considering suggestions and ideas from every level (especially operator's etc) is not allowed to happen.

Draeger Safety UK Operations manager (Vince Smith) has a favourite saying, "with every pair of hands employed comes a free brain". This has become an operation department philosophy and using and improving those free brains through training and education forms a major part of the operations innovational drive. The realization that any individual can have innovational ideas that are worth pursuing is accepted and followed. People are encouraged to partake in educational and vocational courses, contribute to kaizen and action groups etc. Recognition given via for example an operator of the month award, carrying a small financial prize. Nominations for this award made not by management but operational staff. A committee made up of volunteer staffs, who decide on the recipient of the award, considers the nominations. Senior management also holds regular communication meetings (normally monthly) where staff can put forward ideas, suggestions and concerns. These meetings also allow senior management to signal the strategic direction, goals and priorities of the company. As a final example, a weekly brief contains financial information on sales and production output, Information of visitors to the company along with other general items of interest. Briefing sessions held by all supervisors and section managers again give staff an opportunity to give opinions, ideas or ask questions etc. These being directed to the appropriate member of staff or team for consideration and answer the following week. The discussed methods put into place by senior management. Ensure that staff has at least the opportunity to be informed as to company policy, strategic direction and has a platform for communication of ideas etc. that could lead to innovational improvements. These methods reduce to an extremely low level the possibility of 'academic snobbery' at Draeger Safety UK

\subsection{The Finance Barrier}

Innovation also requires finance, eventually any innovational activity brought to fruition and delivering benefit to the organization will require financial expenditure. This expenditure could be on equipment, material for 
trial production, external consultation etc. One of the functions of management is to make the decision as to which projects receive finance, and which do not. Draeger Safety UK has a philosophy of financing innovation whenever such ideas indicate possible improvement. However as with other organizations Draeger Safety UK must balance the finance required in pursuit of any project with the possible financial benefit that project will return. Management also has a responsibility to the originator of ideas etc rejected finance (or any other required resources) to communicate the reason for the idea not being pursued.

Quality also carries high priority; therefore, a project that maintains or improves quality receives finance, even if financial payback is not a result. An example of such a project was the development of an automated piece of equipment to insert high pressure sealing o-rings into a pressure reducer. Three colour-coded seals inserted in a specific order by hand had a possibility of error in insertion order. An action team formed from engineers and assembly operators being established to examine the situation and develop an answer that would eliminate the possible error condition.

The team first formulated the basic characteristics of the device. For example, it must be able to recognize colour, the order of the o-rings must be correct, the device should not insert the rings on error detection and all health and safety requirements must be established and met. This initial general specification then outlined the knowledge required, such as Programmable Logic Control (PLC) programming optical sensor use, control of pneumatic cylinders and knowledge of health and safety rules.

The requirement of PLC programming was unavailable within the organization and therefore required training and the purchase of software to enable generation of PLC programs via computer. While this required a financial expenditure, it brought new knowledge and the required capability to the company. In this manner, working through the requirements, discussing ideas and possibilities, a new process method and piece of equipment answered the initial quality sustainability question was developed by the team working together towards a common goal.

The final solution brought together pneumatics, programmable logic and optical equipment in a pokayoke device that recognizes colour and will not insert the seals, if they are in the wrong order or any are missing.

This device having no financial advantage in the form of improved cycle time, guarantees maintained quality of the operation and thus received the finance and resources of time and manpower required. This example is a demonstration of as (Weatley, 2001) suggests "The human capacity to invent and create is universal". Draeger Safety UK recognizes that people have innate capacity to innovate. All they need is encouragement, backing and engagement in meaningful issues. 


\section{THE SEVEN SOURCES OF INNOVATION}

The question "is innovation inspiration or hard work", is posed by (Drucker, 2002)? With the conclusion that it is largely the latter. He identifies seven sources of innovation he comments "In business innovation rarely springsfrom a flash of inspiration. It arisesfrom a cold-eyed analysis of seven kinds of opportunities". These opportunities being:

1. Unexpected Occurrences.

2. Incongruities.

3. Process Need.

4. Industry and Market Changes.

5. Demographic Changes.

6. Changes in Perception.

7. New Knowledge.

The seven sources will effect various departments of any organization somewhat. The effect being dependant upon and varying according to departmental function. For example, process needs could have high impact on production departments while for sales and marketing this opportunity will have low innovational potential. Thus for some organizational departments some sources will be irrelevant. However put together they account for the majority of innovation opportunities within the overall organization.

\subsection{Unexpected Occurrence}

As one example of unexpected occurrence, the recent heightened threat from terrorist attack has increased the awareness of search and rescue organization to the need for additional standard as well as specialized equipment. In the case of one piece of specialized equipment, a requirement existed for fully working prototype to be available three weeks from first inquiry. During discussions with the leader of the project team, it emerged that a consolidated effort was required from all sections of the company to achieve the three-week deadline using rapid prototyping techniques. Design used high-powered drawing and modeling software (pro-engineer) to use existing components in new configurations. Production engineering and assembly personnel in actually building the apparatus, purchasing working closely with suppliers to secure purchased components and sales clarifying requirements with the customer.

It was only with the cooperation of all departments and staff that allowed a working breathing set to be available within the time limit.

As Wheatley (2001) states, most people are very intelligent. They have figured out how to make things work when it seems impossible, they have 
invented ways to get around roadblocks, they have created their own networks to support and help them learn. These acquired personnel networks come into their own at times such as the development and manufacture of the example above. The usual methodical laid down methods and steps in the development of new products within Draeger Safety UK had to be temporarily circumvented, while maintaining control of design integrity, quality etc. in order to meet such a short deadline. Impromptu meetings being arranged agreements being reached and work carried out when required. This type of unsuspected occurrence requires rapid response and adaptability from the whole workforce, as disruption to normal activities is virtually inevitable under the circumstance. Management must rely on the ability of the staff putting trust in them to accomplish the task. In turn, the staff must use their knowledge and abilities to work in harmony putting trust in each other to achieve the innovational approach required.

\subsection{Incongruities}

Collins dictionary defines incongruous as "inappropriate or out of place". However, Drucker (2002) in his description takes the definition a little further by encompassing such things as necessary operations or procedures performed as part of a production process disliked by the people performing the operation. One such within Draeger Safety UK concerns a piece of equipment used in the production of lung demand valves. The particular piece of equipment used to test the functioning of the valve while some years old is nevertheless extremely reliable. This type of equipment is also used by certification test house (such as Lloyds and TUV) in conformance test of equipment. Thus, saleable products undergo tests on equipment similar to that used to gain certification. While not difficult to use the equipment required several changes of supplied air pressure, air flow rates and respiration cycles per minute during the test. These changes being made by manual adjustment of valves, proving both tiring time consuming and a possible risk of strain to operators. The industrial engineering manager tasked an engineer to as far as possible automate these valve actions. This being completed some months ago with the use of electronic switching and programmable logic controls. To carry on this automation and incorporate computer control. A project team was formed recently and is exploring the possibility of working with local universities to design and develop a replacement breathing test facility that not only carries out the function of existing equipment but incorporates possible future requirements.

While still in the very early stages this project has the possibility of removing the incongruity completely, incorporating data base technology and simplifying data analysis. 


\subsection{Process Needs}

The operations department has the responsibility of manufacture and therefore process need plays a major part in driving innovational change.

The example given above of the seal insertion device is a response to process need and requires no further discussion.

Another prime example of process need driving innovation is the development of a new generation of pneumatic test equipment. The realization of this particular need arose from a growing opinion that the existing test equipment developed some five years ago and state of the art at that time. Could today be improved via technologies not used in the original equipment. This opinion eventually being held by production management engineers and staff operating the equipment. Therefore, the decisions to invest time labour and finance in the development of new test equipment came almost by default. As normal within Draeger Safety UK, an action team established to undertake the development consisted of cross-functional abilities with members tasked to work together maximizing joint ability's to achieve the set objective. However it soon became apparent that while the general technical, abilities where present within the company collaboration with external organizations would be required for the specific detail of some technical aspects. Thus, the team sought assistance from suppliers to specify particular equipment best suited to the needs of the system. Working in collaboration with suppliers of such items as laminar flow equipment, computer digital and analogue signal boards with signal conditioning a detailed, specification of the test equipment resulted. The possibility of commissioning a software supplier to develop software to control the equipment after investigation lead to a decision to develop software internally. Total control of software intellectual property being the prime reason. Internal development also had the advantages of cost. The completed software being designed and programmed by engineers that knew and worked on the package as a whole not just the software. This allowed a system thinking holistic approach Senge (1990) instead of a reductionist approach taken by a company interested in software only. Thus the action team working with test operators suppliers and contractors specified developed and built the next generation of test equipment. An innovational approach bringing together hardware and software in ways new to the organization, providing direct reading of data by computer thereby minimizing risk of data entry error. The system also allowing subsequent data analysis of stored data thus providing information to direct future improvement. 


\subsection{Industry and Market Changes}

Markets are customers driven and Draeger Safety UK responds to customer requirements through continuos product development.

Innovational drive in this area is by a combination of customer requests and internal development and enhancement. The latest developments to Draeger breathing equipment is the move to electronics from the traditional mechanical and pneumatic systems for air warning and pressure indication

These innovations arrived at through cooperation between the development department and suppliers of electronic equipment designing and developing new equipment to suit the applications and environments required.

\subsection{Demographic changes}

Market demographics have changed for not only Draeger Safety UK but also all organizations. The changes to the political scene in China opening markets that were none existent only a few years ago. In answer to these changes, breathing apparatus specifically designed by Draeger Safety UK to meet the requirements of the market is assembled in a recently established plant in China. Thereby using local market knowledge and contacts to expand sales at a higher rate than would be possible if bases within the UK or Europe were used to service the Chinese market.

\subsection{Changes in Perception}

Example already given can also come under the heading of changes in perception. The development of the seal pack from the perception that quality improvement would result. Development of new pneumatic test equipment from a growing realization that new technology existed that could improve this function. Breathing test equipment development from the change in perception towards automation and computer control instead of manual operation of valves and hand written records of test data can also come into the changing perception category.

\subsection{New knowledge}

"Application of new idea or principles based on totally new knowledge, these have long lead times but can be the history making innovations" (Drucker, 2002). 
The examples of the seal pack and pneumatics test equipment are both of application of new knowledge. While not exactly in the history making division, for Draeger Safety UK such applications have supplied the innovational improvements allowing year on year achievement of improved overall results. Application of new knowledge is taking place on a daily basis within the organization ranging from knowledge gained from customer's opinions incorporated into products, to knowledge of new production techniques. Therefore, the knowledge gained by individuals from whatever quarter and used in continuing improvements is the innovational lifeblood of the company.

\section{INNOVATION IN TERMS OF THE VIABLE SYSTEMS MODEL}

\subsection{The Viable System and Innovation}

Organizations can be viewed as viable systems; such viable systems have the objective of survival, the requirement to carry on into the future (Beer, 2000). Therefore if innovation is essential to continued survival as argued by writers such as(Drucker, 2000), (Senge, 1990), (Wheatley, 2001), (Eppinger, 2001) it must form part of the viable system. The model has five sub systems one of which (system four) deals with the "outside and then" "Outside" being described as the problematic external environment and "then" referring to the future. Thus, system four deals with innovation when formulating new processes, markets, products etc. In short, innovation is the responsibility of system four within the viable system model. Thus as all viable systems must by definition have a system four innovation is possible within all viable systems.

\subsection{The Recursion effect on innovation}

Viable systems are also considered to be recursive, the recursive systems theory states "In a recursive organizational structurally, any viable system contains and is contained in, a viable system" (Beer 2000, p. 118). Viable systems can be envisaged as an infinite set of Chinese boxes or Russian dolls each containing and being contained within another viable systems at higher and lower levels of recursion. These levels of recursion extend from the "macrocosmic to the microcosmic" (Beer, 2000, p.312). In an organizational context, recursive viable systems are considered as the various organizational levels from holding company through divisions to plants then 
departments on to departmental sections then to individual personnel. Each of these levels forms a recursive organizational viable system contained in the former and containing the latter. Therefore, if each recursion by definition must contain a system four then innovation is possible at any recursive level.

Figure 2 shows a partial view of the levels of recursion for Draeger safety in the Chinese box format. The recursive levels shown in Figure 2 are only one of many possibilities. For example at the Draeger Safety Level, Draeger Medical or Gas Detection exists with recursions applicable to those divisions.

When viewed as a viable system it becomes obvious that the focus of innovation will have a close relationship with the functions carried out by the system. Therefore, the level of recursion heavily effects the focus of innovational activity. It is also possible for strategy to pass down from level to level driving innovation in the desired direction at each level.

This trickle down effect is possible via a command channel running between each recursive level. It is via the command channel that one level influences and directs the general direction of the system occupying the level below. In the case of strategy the command channels between systems maintains the common general focus of all levels. The trickle down effect proved a driving force for improvement and cost reduction within the operations department of Draeger Safety, as outlined in section 4.3

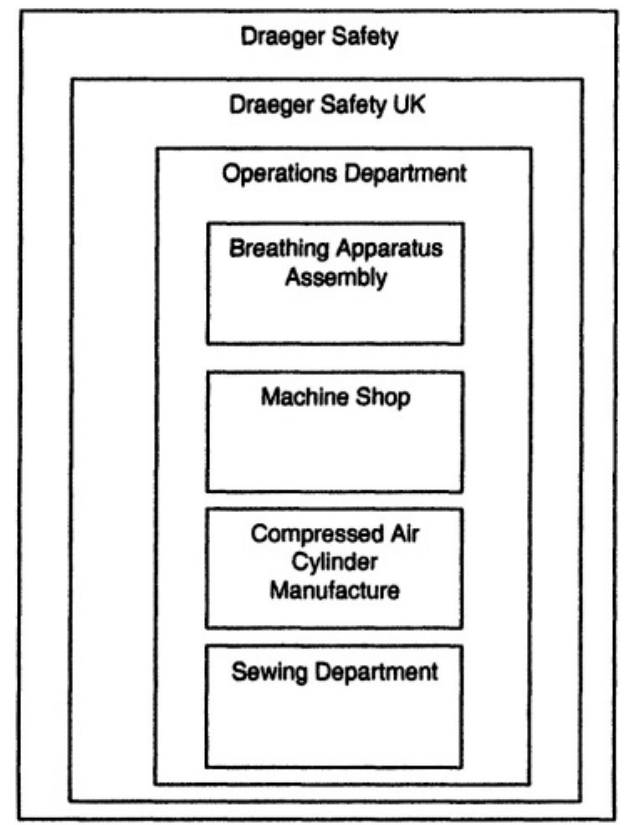

Figure 2. Levels of Recursion for Draeger Safety UK 


\subsection{Viable Systems and Innovation at Work.}

In 1999, the board of Draeger (Parent Company of Draeger Safety UK) decided as part of corporate strategy to reduce the cost of poor quality by $50 \%$. This became a directive and trickled down via the command channel from one level to the next. At each level while the goal was the same the innovation method used varied according to the function of the recursive level. Upon reaching the Operations department of Draeger safety, it was decided that an action group would be given the task of formulating methods and procedures to meet the directive. It is not the intention to detail the thinking and academic principles used by the group. A paper by Brown \& Sice entitled "A Knowledge Management Approach to Reducing the Cost of Poor Quality-the Draeger Safety UK Ltd. Case" and presented at the UK Academy for Information Systems (UKAIS) conference 2003, detailed these methods and theories.

In short, it was decided to produce an IT system to collect data on items reworked and rejected. System output information being used to identify components and operations having high rework or reject costs. Once identified kaizen or action groups being formed to concentrate on improvements that would result in a reduction of poor quality cost. To enable production and operation of the IT system required the assistance and cooperation of assembly staff. Information on problems encountered and the time taken to rectify those problems being best obtained from the people actually dealing on a daily basis with rework. The principles of trust in each other that data given and collected was accurate and used only for constructive problem identification and resolution became an essential part of the successful operation of the Cost of Poor Quality (COPQ) program. Such trust and cooperation being essential in today's workplace if innovation is to play a part Wheatley (2001).

Using the IT system to identify high cost areas and teams to investigate and implement improvements resulted by the end of 2001 in a reduction of the cost of poor quality from $3.5 \%$ to $0.5 \%$ of manufacturing costs. The success of this approach can be attributed to the people at the operational level taking ownership of the IT system, examining the outputs and deciding on relevant actions. It was people that provided the solutions, people that implemented them and people that provided the innovation. The IT system providing a channel to gather data and convert that data to useful information in a form relevant to the people at the operational level of recursion. Thus in the case of COPQ an innovational method was devised, implemented and operated by the people at that level to answer a directive carried down the command channel from a higher level. 
A final point exemplified by COPQ is that of data and information. As the people who would eventually operate the system were closely involved in development, the language and terminology used for data and information was the language of the production not the technical or IT department. Thus, this deliberate use of the production language while possibly not technically accurate had two beneficial effects. The first is the reduction of transaction ambiguities. Beer (2000) maintains in the 'third principle of organization' that whenever information transmitted on any channel crossing a boundary undergoes transaction. Such a boundary exists between data collection and information production in the form of the IT system. When the language of the IT system differs from the language of the users, interpretation can introduce ambiguities and translation of meaning. Resulting in misinterpretation of data collected and information then supplied. Tailoring the language of the system to the language of the user reduces this possibility. The second advantage is empowerment through involvement. Users immediately became owners after all, they had a role in the look and feel of the system, they decided how and what data was to be collected, it was the users that decided the format of output information. Therefore, the involvement and empowerment of the people that actually use the system played a substantial role in the success obtained.

\section{CONCLUSION}

That Draeger Safety UK believes that its people are the basis of innovation and future success is without doubt. The development of the operations training department, staff development via training and education coupled with involvement and empowerment all point in this direction. However, the all-important question is has this approach delivered innovation as defined in the introduction leading to organizational benefits? To answer this question results will be examined from two distinct views, the hard issues of figures and the soft issues of opinion.

Factual examples of hard issues show improvements in all directions. Within production, for example the lung demand assembly area some two years ago produced an average of between 200 and 210 units per day, while the present average is 300 to 330 units per day. A $50 \%$ increase in production with the same number of people. Sales and profit targets have increased and been achieved for the past several years. Profitability measures such as profit per employee, return on investment etc. are amongst the highest within the Draeger group. In addition, investment for the future is increasing with additional building to enable expansion under way. The staff of Draeger Safety has embraced the idea of vocational training and 
education, with 191 people achieving nationally recognized NVQ, management and other courses up to higher degree level in the last three years. With a total workforce of 356 this equates to $54 \%$ of the workforce engaged in educational improvement activities.

For the soft issues of opinion and perception, the following comments, and extract from written documents are indications of the beliefs and opinions prevalent within the staff of Draeger Safety UK and outside bodies associated with the company.

During a series of informal interviews on quality perception and inquiry, it emerged that the general opinion was in favour of the approach adopted. The people based approach had gained favour with the majority of staff, who felt that it had improved the quality of working life. Specific comments included

"I like working here, I feel respected as a person, things like that"

"This is a much better place than it was ten years ago"

"It is a far more relaxed atmosphere in the machine shop now and we are still getting the work done"

"I find people here are particularly happy, contented you know willing to talk to you"

"I like working with other people, I like being in control and achieving what I set out to do"

An NVQ examiner writing to a Draeger Safety UK training officers states:

"Your organization sees the ongoing training and development of staff as a key aspect of success in the marketplace"

While a member of staff, in an email to a course tutor writes:

"I have now realized that most folk who 'care' are passionate about their role in the work environment and desire to do well for their boss and the company"

The small selections of both hard and soft issues given above nevertheless are indicators of the success of the improvement through innovation via staff knowledge and involvement taken by Draeger Safety UK.

The answer to the question "has this approach delivered innovation as defined in the introduction leading to organizational benefits", is a 
resounding yes. However as innovation by definition is a never ending quest, then the aim of improvement through innovation is likewise never ending. As an organization Draeger Safety UK will not sit back and think we have done it we are there. For the simple reason, there is always another improvement awaiting discovery. Draeger Safety UK has chosen to put faith in its people via empowerment invest in staff development and make innovation and continuos improvement in all aspects of its business a cornerstone of it philosophy. For this organization, it has paid dividends financially and culturally; putting Draeger Safety UK well placed in today's rapidly changing market environment that requires innovational adaptation to survive and continue as an organizational viable system.

\section{REFERENCES}

Argyris C (1998), Empowerment the Emperors New Cloths, Harvard Business Review May June 1998

Beer S. (1990): The Heart of Enterprise, JohnWiley \& Sons

Bohm D, Factor D, Garrett P (1991), Dialouge - A Proposal,

URL http: //www. muc. de/ heuvel/dialogue_proposal. html 21/10/03

Davenport T, \& Prusak L (2000), Working Knowledge, How Organizations Manage What They Know, Harvard Business School Press

Drucker P (2002), The Discipline of Innovation, Harvard Business Review Aug 2002 Vol. 80

Eppinger S. D (20001), Innovationat the Speed of Information. Harvard Business Review Jan 2001 Vol. 79

Mintzberg H (1996) Ten Ideas Designed to Rile Everyone Who Cares About Management, Harvard Business Review July - August 1996

Morris D (1969), The Human Zoo, Jonathan Cape

Morris D (1967) The Naked Ape: A zoologists study of the human animal, Jonathan Cape

Senge P (1990), The Fifth Discipline: The Art \& Practice of the Learning Organization, Bantam Doubleday

Handy C (1997), The Citizen Company, Source Extract from the Hungry Spirit 1997, pp179204, in Creativity Innovation and Change The Open University

Teece D. J (2001) Startegies for Managing Knowledge Assets: the Role of Firm Structure and Industrial Contex, in Managing Industrial Knowledge ed Nonaka \& Teece, Sage Publications

Teece D. J (2000), Managing Knowledge Assets in Diverse Industrial Context, in Knowledge Horizons: The Present and the Promise of Knowledge Management, Ed Despres C \& Chauvel D.

Wheatley M J (2001), Innovation Means Relying on Everyone's Creativity. Leader to Leader No20 Spring 2001

Willets L. G (1996), The Best Ways to Survive Reeneineering, Expert Tips on How to Reinvent Your Attitude

Url: http://www.reengineering.com/articles/sept96/reengsurvival.htm 16/10/03 